Original Article

\title{
Functional limitations due to foot involvement in spondyloarthritis
}

\author{
Nihal Ozaras, $\mathrm{MD}^{1)^{*}}$, Nuri Havan, MD²), Emine Poyraz, MD ${ }^{1)}$, Aylin Rezvani, MD $^{1)}$, \\ Teoman Aydin, MD ${ }^{1)}$ \\ 1) Department of Physical Medicine and Rehabilitation, Bezmialem Vakif University: Istanbul, Turkey \\ 2) Department of Radiology, Afsin State Hospital, Turkey
}

\begin{abstract}
Purpose] Spondyloarthritis is a major inflammatory disease followed-up in the rheumatology clinics, foot involvement in spodyloarthritis is common. The functional states of patients with spondyloarthritis are usually evaluated globally. The aim of this study was to assess the foot involvement-related functional limitations in patients with spondyloarthritis. [Subjects and Methods] Patients with ankylosing spondylitis and psoriatic arthritis with foot pain more than 4 weeks who underwent anteroposterior and lateral feet radiography were enrolled into the study. A "clinical findings score" was calculated by assigning 1 point for every finding of swelling, redness, and tenderness. C-reactive protein and erythrocyte sedimentation rate were used as serum markers for disease activity. Foot radiograms were evaluated using the spondyloarthropathy tarsal radiographic index and the foot-related functional state of patients was determined by the Turkish version of the Foot and Ankle Outcome Score. [Results] There were no relationships between Foot and Ankle Outcome Score subscales and clinical findings score, serum markers, or radiologic score. Pain and symptoms subscale scores were result positively correlated with activity of daily living, sport and recreation, and quality of life subscale scores. [Conclusion] Pain and symptoms are the main determinants of foot-related functional limitations in spondyloarthritis. Key words: Foot, Spondyloarthritis, Foot and Ankle Outcome Score
\end{abstract}

(This article was submitted Jan. 25, 2016, and was accepted Apr. 7, 2016)

\section{INTRODUCTION}

Spondyloarthritis (SpA) is a group of rheumatic diseases characterized by inflammatory back pain, peripheral oligoarthritis, enthesitis, and/or extraarticular manifestations ${ }^{1)}$. Ankylosing spondylitis (AS) and psoriatic arthritis (PsA) are the most frequently seen SpA subtypes in rheumatology units ${ }^{2-4)}$. Foot involvement in SpA is not uncommon and enthesitis, erosive changes, or ankylosis are the main symptoms ${ }^{5,6}$. This involvement may affect foot functions negatively, similar to rheumatoid arthritis (RA) ${ }^{7}$. In rheumatology units, the functional states of patients with SpA are usually evaluated using Bath Ankylosing Spondylitis Functional Index (BASFI) or other similar scales globally. However, these assessments may underestimate the foot-related functional limitations in these patients.

The Foot and Ankle Outcome Score (FAOS) is a scale measuring the foot-related functional limitations in the disorders affecting the foot ${ }^{7-10}$. It consists of 5 subscales: pain, symptoms, activities of daily living (ADL), function in sport and recreation (Sport-Rec), and foot and ankle-related quality of life (QoL). The Turkish version of FAOS is a valid and reliable instrument to assess foot and ankle related problems ${ }^{11)}$.

The aim of this study was to assess specifically the functional limitations caused by foot involvement in patients with SpA.

*Corresponding author. Nihal Ozaras (E-mail: nihalozaras@yahoo.com)

(C2016 The Society of Physical Therapy Science. Published by IPEC Inc.

This is an open-access article distributed under the terms of the Creative Commons Attribution Non-Commercial No Derivatives (by-nc-nd) License $<$ http://creativecommons.org/licenses/by-nc-nd/4.0/>. 


\section{SUBJECTS AND METHODS}

Patients with AS and PsA aged 18-70 years, with foot pain for more than 4 weeks who underwent anteroposterior (AP) and lateral (L) feet radiography were included into the study. They met the modified New York criteria for AS and Moll-Wright criteria for PsA ${ }^{12,13)}$. Informed consent was obtained from all patients. Patients who had flatfoot, previous foot surgery, or any other foot disorder unrelated to $\mathrm{SpA}$, and who had a systemic disease such as diabetes or hyperthyroidism were excluded. Ethical approval for this study was obtained from the ethical committee of the university where the study was conducted.

The demographic features of subjects were determined. The clinical findings of foot involvement were assessed by observing for swelling, redness, or tenderness. To obtain a numerical value, a "clinical findings score" (CFS) was calculated by giving 1 point for every finding on one foot [swelling: 1 point, redness: 1 point, tenderness: 1 point; the maximum CFS score was 6 for the two feet]. The radiologic involvement of the foot was evaluated by the spondyloarthropathy tarsal radiographic index (SpA-TRI), which is a valid and reliable radiologic index developed specifically for the assessment of foot involvement in $\mathrm{SpA}$, and is suitable for use with two or more X-ray projections. It has five points; 0: normal, 1: osteopenia or suspicious findings, 2: definite joint space narrowing, bony erosions, periosteal whiskering, enthesophytes, 3: paraarticular enthesophytes/incomplete bridging, 4: bony ankylosis/joint space fusion or complete bridging. The maximum SpA-TRI score for the two feet (total SpA-TRI score) is $56^{14}$. Foot X-ray images were evaluated by a radiologist who had no information about the clinical status of subjects. Talonavicular, calcaneocuboid, intercuneiform, cuneonavicular, and subtalar joints, and the calcaneal attachments of the Achilles tendon and plantar fascia (7 places) were assessed using the SpA-TRI.

The foot-related functional status of patients was determined by the Turkish version of the FAOS. It was a self-assessment questionnaire filled by patients themselves. FAOS is calculated by a specific equation, and " 100 " indicates no problems while " 0 " indicates extreme problems ${ }^{8}$. Since the pain assessment was achieved in detail by FAOS, no other pain assessment scale was needed.

C-reactive protein (CRP) and erythrocyte sedimentation rate (ESR) were used as serum markers for disease activity.

Statistical analysis was done using Statistical Package for Social Studies, version 10.0. Pearson correlation analysis was used to reveal the relationships between parameters.

\section{RESULTS}

Thirty patients with SpA (14 AS, 16 PsA) with a mean age of 49 years (range 26-70 years) completed the study. The mean FAOS subscale scores were as follows: pain $=58.70 \pm 21.75$, symptoms $=64.88 \pm 26.05$, ADL $=66.27 \pm 22.56$, Sport$\mathrm{Rec}=44.33 \pm 26.42$, and $\mathrm{QoL}=42.08 \pm 24.99$. Pain subscale scores correlated positively with ADL, Sport-Rec, and QoL subscale scores. Symptoms subscale score also positively correlated with ADL, Sport-Rec, and QoL subscale scores (Table 1). Pain and symptoms subscale scores positively correlated with each other (r: $0.679, \mathrm{p}<0.001)$.

The mean CFS was $1.5(0-4)$. This value demonstrated that although patients had foot pain, they did not have prominent physical examination findings. The mean CRP and ESR were $1.1(0.1-8.5) \mathrm{mg} / \mathrm{dl}$ and $32(7-100) \mathrm{mm} / \mathrm{h}$, respectively, showing low disease activity. There were no relationships between FAOS subscale scores and CFS or serum markers (CRP/ ESR).

The mean SpA-TRI score was 7.7 (0-24) and no correlation was found between FAOS subscale scores and radiologic score.

\section{DISCUSSION}

Foot disorders may affect mobility and life quality significantly. AS frequently involves the foot; the Achilles tendon is the second most common site of enthesitis after the chondro-sternal junction, and the ankle is the second most common site for peripheral joint disease after the $\mathrm{knee}^{6}$. The involvement of the ankle and small joints of the foot is also frequent in PsA ${ }^{15}$. These effects of AS or PsA on the foot may lead to functional limitations. The functional states and quality of life of patients with SpA are usually evaluated using questionnaires such as BASFI, Health Assessment Questionnaire for Spondyloarthropathies (HAQ-S), Ankylosing Spondylitis Quality of Life Questionnaire (ASQoL), or PsA-specific Quality of Life Questionnaire (PsAQoL) ${ }^{16-19)}$. However, these questionnaires evaluate the functional activities in a global manner

Table 1. Positive correlation between Pain and Symptoms subscale scores with other FAOS subscale scores

\begin{tabular}{lllcl}
\hline & & ADL & Sport-Rec & QoL \\
\hline Symptoms & $\mathrm{r}$ & $0.749^{*}$ & $0.693^{*}$ & $0.552^{*}$ \\
Pain & $\mathrm{r}$ & $0.875^{*}$ & $0.872^{*}$ & $0.629^{*}$ \\
\hline
\end{tabular}

FAOS: The Foot and Ankle Outcome Score, ADL: function in daily living, Sport-Rec:

functions in sport and recreation, QoL: quality of life. ${ }^{*} \mathrm{p}<0.01$ 
without considering the specific cause of the limitation. Therefore, the functional cost of foot involvement cannot be assessed clearly with these indices leading to underestimation.

FAOS is a 42-item questionnaire developed for the assessment of functional limitations after ankle ligament reconstruction, but it was also used in other disorders affecting the foot such as hallux valgus and rheumatoid arthritis ${ }^{7-9)}$. It has 5 subscales; Pain, Symptoms, ADL, Sport-Rec, and QoL. Pain subscale include 9 questions evaluating the frequency and severity of pain in certain situations such as walking on flat surface or at night while in bed. Symptoms subscale has 7 questions assessing the stiffness, swelling, and movement properties of the foot/ankle. The ADL and Sport-Rec subscales evaluate the degree of difficulty experienced due to foot/ankle disorders in functional activities. The fifth subscale, QoL, focuses on the awareness of the foot/ankle problem ${ }^{8,11}$. Pain and symptoms subscale scores significantly and positively correlated with each other and with ADL, Sport-Rec, and QoL subscale scores. Pain and symptoms such as stiffness or range of motion loss, were the major cause of limitation of functional activities in patients with SpA.

Plain radiography is a routinely used imaging technique in the evaluation of radiologic involvement in rheumatic diseases. SpA-TRI is the radiologic index developed specifically for the assessment of foot involvement in SpA. In this study, no correlation was found between SpA-TRI and FAOS subscale scores. The mean SpA-TRI score was 7, a very low score when compared with the maximum score of 56. It could be speculated that although patients had symptoms, radiography did not show the involvement clearly, and therefore, no statistically significant results were obtained. The magnetic resonance imaging technique is quite successful in demonstrating very early changes at the feet even in patients with asymptomatic AS and PsA ${ }^{20,21)}$. Therefore, this should be the preferred technique for future studies.

In this study, the relationships between the FAOS subscale scores and CFS and serum markers were also assessed. There were no relationships between FAOS subscale scores and CFS. The foot is composed of small joints and their examination is relatively difficult than that of the large joints. The inflammatory changes producing pain in these small joints may not always lead to swelling, redness, or tenderness. These reasons may explain the lack of a relationship between CFS and FAOS subscale scores. In our study, CRP and ESR values were distributed in a wide range $(0.1-8.5 \mathrm{mg} / \mathrm{dl}$ and $7-100 \mathrm{~mm} / \mathrm{h}$, respectively) showing that foot involvement may not be directly affected from the disease activity. This hypothesis remains to be clarified with studies having a larger sample size.

In conclusion, rheumatic pain, resulting from the inflammatory changes in the joints and related structures, is a very important clinical problem disturbing the mood, sleep, and quality of life of patients ${ }^{22-24)}$. It is the most common presenting symptom of rheumatic diseases of the foot and may precede clinical and radiologic findings ${ }^{25)}$. This study demonstrated that foot pain in patients with SpA might result in significant foot-related functional limitation. Therefore, foot involvement and its functional results should be evaluated separately regardless of the global functional state and disease activity of the patient. To improve pain and function physical therapy modalities or orthosis may be used ${ }^{26,27)}$. More studies about the foot involvement at the early and late stages of the disease are needed and the possible treatment approaches must be investigated.

\section{REFERENCES}

1) Baraliakos X, Braun J: Spondyloarthritides. Best Pract Res Clin Rheumatol, 2011, 25: 825-842. [Medline] [CrossRef]

2) Braun J: Therapy of spondyloarthritides. Adv Exp Med Biol, 2009, 649: 133-147. [Medline] [CrossRef]

3) van den Berg R, van der Heijde DM: How should we diagnose spondyloarthritis according to the ASAS classification criteria: a guide for practicing physicians. Pol Arch Med Wewn, 2010, 120: 452-457. [Medline]

4) Zochling J, Smith EU: Seronegative spondyloarthritis. Best Pract Res Clin Rheumatol, 2010, 24: 747-756. [Medline] [CrossRef]

5) Moll JM: Seronegative arthropathies in the foot. Baillieres Clin Rheumatol, 1987, 1: 289-314. [Medline] [CrossRef]

6) Aggarwal R, Malaviya AN: Clinical characteristics of patients with ankylosing spondylitis in India. Clin Rheumatol, 2009, 28: 1199-1205. [Medline] [CrossRef]

7) Göksel Karatepe A, Günaydin R, Adibelli ZH, et al.: Foot deformities in patients with rheumatoid arthritis: the relationship with foot functions. Int J Rheum Dis, 2010, 13: 158-163. [Medline] [CrossRef]

8) Roos EM, Brandsson S, Karlsson J: Validation of the foot and ankle outcome score for ankle ligament reconstruction. Foot Ankle Int, 2001 , 22 : 788-794. [Medline]

9) Chen L, Lyman S, Do H, et al.: Validation of foot and ankle outcome score for hallux valgus. Foot Ankle Int, 2012, 33: 1145-1155. [Medline] [CrossRef]

10) Kim H, Chung E, Lee BH: A comparison of the foot and ankle condition between elite athletes and non-athletes. J Phys Ther Sci, 2013, 25: 1269-1272. [Medline] [CrossRef]

11) Karatepe AG, Günaydin R, Kaya T, et al.: Validation of the Turkish version of the foot and ankle outcome score. Rheumatol Int, 2009, 30: 169-173. [Medline] [CrossRef]

12) Pacheco-Tena C, Londoño JD, Cazarín-Barrientos J, et al.: Development of a radiographic index to assess the tarsal involvement in patients with spondyloarthropathies. Ann Rheum Dis, 2002, 61: 330-334. [Medline] [CrossRef]

13) van der Linden S, Valkenburg HA, Cats A: Evaluation of diagnostic criteria for ankylosing spondylitis. A proposal for modification of the New York criteria. Arthritis Rheum, 1984, 27: 361-368. [Medline] [CrossRef]

14) Moll JM, Wright V: Psoriatic arthritis. Semin Arthritis Rheum, 1973, 3: 55-78. [Medline] [CrossRef]

15) Kane D, Stafford L, Bresnihan B, et al.: A classification study of clinical subsets in an inception cohort of early psoriatic peripheral arthritis - 'DIP or not DIP revisited'. Rheumatology (Oxford), 2003, 42: 1469-1476. [Medline] [CrossRef] 
16) Calin A, Jones SD, Garrett SL, et al.: Bath Ankylosing Spondylitis Functional Index. Br J Rheumatol, 1995, 34: 793-794. [Medline] [CrossRef]

17) Daltroy LH, Larson MG, Roberts NW, et al.: A modification of the Health Assessment Questionnaire for the spondyloarthropathies. J Rheumatol, 1990, 17: 946-950. [Medline]

18) Doward LC, Spoorenberg A, Cook SA, et al.: Development of the ASQoL: a quality of life instrument specific to ankylosing spondylitis. Ann Rheum Dis, 2003, 62: 20-26. [Medline] [CrossRef]

19) McKenna SP, Doward LC, Whalley D, et al.: Development of the PsAQoL: a quality of life instrument specific to psoriatic arthritis. Ann Rheum Dis, 2004, 63: 162-169. [Medline] [CrossRef]

20) Erdem CZ, Sarikaya S, Erdem LO, et al.: MR imaging features of foot involvement in ankylosing spondylitis. Eur J Radiol, 2005, 53: 110-119. [Medline] [CrossRef]

21) Erdem CZ, Tekin NS, Sarikaya S, et al.: MR imaging features of foot involvement in patients with psoriasis. Eur J Radiol, 2008, 67: 521-525. [Medline] [CrossRef]

22) Fitzcharles MA, Shir Y: Management of chronic pain in the rheumatic diseases with insights for the clinician. Ther Adv Musculoskelet Dis, 2011, 3: 179-190. [Medline] [CrossRef]

23) Callis Duffin K, Wong B, Horn EJ, et al.: Psoriatic arthritis is a strong predictor of sleep interference in patients with psoriasis. J Am Acad Dermatol, 2009, 60: 604-608. [Medline] [CrossRef]

24) Batmaz İ, Sarıy1ldı MA, Dilek B, et al.: Sleep quality and associated factors in ankylosing spondylitis: relationship with disease parameters, psychological status and quality of life. Rheumatol Int, 2013, 33: 1039-1045. [Medline] [CrossRef]

25) Frizziero A, Bonsangue V, Trevisan M, et al.: Foot tendinopathies in rheumatic diseases: etiopathogenesis, clinical manifestations and therapeutic options. Clin Rheumatol, 2013, 32: 547-555. [Medline] [CrossRef]

26) Shim JM: The effects of wet heat and dry heat on the gait and feet of healthy adults. J Phys Ther Sci, 2014, 26: 183-185. [Medline] [CrossRef]

27) Li CY, Goto T, Inoue A, et al.: Effects of foot orthosis used for rheumatoid arthritic patients on foot pressure. Orthop Traumatol, 2000, 49: 520-524. [CrossRef] 